\title{
CALCIFYING TENDINOPATHY: A LOCAL OR A SYSTEMIC CONDITION?
}

Benno Ejnisman' ${ }^{2}$, Carlos Vicente Andreoli ${ }^{2}$, Gustavo Cará Monteiro², Alberto de Castro Pocchini ${ }^{2}$, Carina Cohen ${ }^{2}$, Simone Tortato ${ }^{3}$, Marcelo Marques Khede Franklin ${ }^{3}$, Arthur Beber Machado ${ }^{3}$, Moisés Cohen ${ }^{4}$

\section{ABSTRACT}

Objective: To evaluate the relationship between cases of calcifying tendinopathy of the shoulder and symptomatic metabolic diseases such as kidney stones, gallstones and gout. Methods: Calcifying tendinopathy of the shoulder was diagnosed in 63 patients between May 2007 and September 2011. All the patients were treated by the same orthopedic surgeon and were interviewed to gather the following data: age at diagnosis, sex, affected side, dominant side, body mass index (BMI), smoking status and previous histories of kidney stones, gallstones or gout. For statistical analysis, a control group of 63 patients with similar demographic characteristics was used. Results: Among the 63 patients with calcifying tendinopathy of the shoulder, $35(56 \%)$ were male. The right side was affected in 38 patients
$(60 \%)$ and the average age was 48.2 years. Thirty-one patients (49\%) had histories involving some of the metabolic diseases investigated: 20 patients (32\%) reported kidney stones, six (9.5\%) gallstones, four $(6.3 \%)$ gout and one $(2 \%)$ concurrent diagnoses of kidney stones and gout. In the control group, eleven patients $(17 \%)$ had histories involving some of the metabolic diseases investigated: six patients $(9.5 \%)$ reported kidney stones, four $(6.3 \%)$ gallstones and one (1.6\%) gout. Conclusions: The high frequency of nephrolithiasis in patients with calcifying tendinopathy of the shoulder in our study suggests that there are common mechanisms in the pathophysiology of these disorders. Better understanding of these diseases may enable improvement of diagnostics and treatments.

Keywords - Tendinitis; Metabolic Diseases; Nephrolithiasis

\section{INTRODUCTION}

Calcifying tendinopathy is a common disorder of the shoulder, of unknown etiology, characterized by deposition of calcium crystals inside one or more tendons of the rotator cuff ${ }^{(1)}$. It affects around $3 \%$ of adults and, of these, one third start to show symptoms within three years. In painful shoulders, it may be diagnosed in around $7 \%$ of the cases. It occurs especially in female patients between the fourth and sixth decades of life ${ }^{(2,3)}$.

These calcifications occur with greatest frequency in the supraspinatus tendon (51 to $90 \%$ ), followed by cases in the tendons of the infraspinatus and teres minor. The subscapularis is the least affected tendon, in only $3 \%$ of the cases ${ }^{(2,3)}$.
Although the etiology is still not completely understood, it is known that deposition of calcium hydroxyapatite occurs in the affected tendon, with consequent spontaneous reabsorption and tendon healing $^{(2)}$. Tissue hypoxia and localized pressure have already been reported as causal factors. Two different processes for formation of calcium deposits have been proposed: degenerative and reactive calcification ${ }^{(4)}$.

The degenerative hypothesis, which was proposed by Codman, correlates tissue hypovascularization with consequent fibrosis, necrosis and local calcification. The advocates of this theory generally do not take into consideration the typical age distribution of the patients affected, the course of the disease and the morphological characteristics of the calcification.

1 - PhD in Orthopedics. Head of the Shoulder Group, Sports Traumatology Center, Federal University of São Paulo (CETE/Unifesp), São Paulo, SP, Brazil.

2 - Attending Physician at the Sports Traumatology Center, Federal University of São Paulo (CETE/Unifesp), São Paulo, SP, Brazil.

3 - Trainee Physician in the Shoulder Group, Sports Traumatology Center, Federal University of São Paulo (CETE/Unifesp), São Paulo, SP, Brazil.

4 - Head of the Department of Orthopedics and Traumatology, Federal University of São Paulo (Unifesp), São Paulo, SP, Brazil

Work performed in the Shoulder Group, Sports Traumatology Center, Federal University of São Paulo (CETE/Unifesp), São Paulo, SP.

Correspondence: Simone Tortato, Rua Borges Lagoa 783, $5^{\circ}$ andar, Vila Clementino, 04038-032 São Paulo, SP. E-mail: simone.t@uol.com.br

Work received for publication: August 22, 2011; accepted for publication: November 10, 2011.

The authors declare that there was no conflict of interest in conducting this work 
According to the hypothesis of reactive calcification, the evolution of calcifying tendinopathy can be divided into three phases: pre-calcification, calcification and post-calcification ${ }^{(4)}$.

Some authors have also correlated calcifying tendinopathy with a genetic predisposition, through higher levels of human leukocytic antigen A1 (HLA-A1) in the patients affected, in comparison with the healthy population. This result was not found by other authors ${ }^{(4,5)}$.

There are few reports in the literature on diseases related to calcifying tendinopathy. Harvie et $\mathrm{al}^{(7)}$ reported associations with certain hormonal alterations, such as diabetes mellitus, hypothyroidism and disorders of the menstrual cycle. However, there are no studies in the literature correlating calcifying tendinopathy with metabolic diseases such as renal lithiasis, gallstones and gout.

The aim of the present study was to determine the frequency of associations of symptomatic metabolic diseases with calcifying tendinopathy of the shoulder.

\section{MATERIALS AND METHODS}

Between May 2007 and September 2011, 63 patients with calcifying tendinopathy of the shoulder were diagnosed and treated at our clinic, by the same orthopedic surgeon. Cases of dystrophic calcification associated with rotator cuff injuries were excluded, as were various other cases that involved periarticular calcifications, such as fractures and dislocations.

All the 63 patients retrospectively agreed to participate in the study and were then asked about their previous history of symptomatic metabolic diseases, which included renal lithiasis, gallstones and gout. Data on age at the time of diagnosis, sex, side affected, dominant side, body mass index and smoking were also gathered.

For comparative analysis on the results, a control group formed by 63 patients from the general orthopedics outpatient clinic was used. These individuals presented confirmed diagnoses of some other orthopedic or traumatic disorder. Among these, patients with calcifying tendinopathy of the shoulder or diseases of calcifying nature in other regions, such as calcifying tendinopathy of the calcaneus and triceps, were excluded. In the same way as in the study group, all the patients in the control group agreed to participate in the study, and then data were gathered regarding their age, sex, body mass index, smoking habits and pre- vious histories of renal lithiasis, gallstones and gout.

To make comparisons between the groups in relation to the variables, the Student $t$ test, chi-square test and Fisher exact test were used. P-values $<0.005$ were taken to indicate statistical significance. The data were organized in Excel spreadsheets and were analyzed using the Statistica software, version 8.0.

\section{RESULTS}

\section{Calcifying tendinopathy group}

Among the 63 patients who presented calcifying tendinopathy of the shoulder, $35(56 \%)$ were male. The right side was affected in 38 patients $(60 \%)$, the left side in $17(27 \%)$ and bilaterality was recorded in eight cases $(13 \%)$.

The mean age at the time when calcifying tendinopathy was diagnosed was 48.2 years. The body mass index (BMI) of this group was calculated as $27 \mathrm{~kg} / \mathrm{m}^{2}$.

Among the 63 patients, 31 (49\%) presented previous histories of some of the metabolic diseases under investigation: 20 patients $(32 \%)$ with histories of renal lithiasis, six $(9.5 \%)$ with gallstones and four $(6.3 \%)$ with gout. One patient $(2 \%)$ presented concomitant diagnoses of renal lithiasis and gout. Eight patients $(13 \%)$ reported that they were smokers.

\section{Control group}

The control group was formed by 63 patients with demographic characteristics similar to those of the calcifying tendinopathy group. In the control group, 32 $(51 \%)$ were male. The mean age was 50.5 years. The mean BMI of this group was calculated as $26.1 \mathrm{~kg} / \mathrm{m}^{2}$.

Among these 63 patients, 11 (17\%) presented previous histories of some of the metabolic diseases investigated: six patients $(9.5 \%)$ with histories of renal lithiasis, flour $(6.3 \%)$ with gallstones and one $(1.6 \%)$ with gout. Fourteen patients $(22 \%)$ reported that they were smokers (Tables 1 and 2).

\begin{tabular}{c|c|c|c|c} 
Table 1 - Results from Student's t test. \\
\hline Variable & Group & Mean & SD & $\mathbf{p}$ \\
\hline \multirow{4}{*}{ Age } & Control & 50.5 & 10.6 & \\
\cline { 2 - 5 } & Calcifying tendinopathy & 48.2 & 9.8 & 0.213 \\
\cline { 2 - 5 } & Total & 49.4 & 10.2 & \\
\hline \multirow{3}{*}{ BMI } & Control & 26.1 & 4.2 & \\
\cline { 2 - 5 } & Calcifying tendinopathy & 27.0 & 5.0 & 0.255 \\
\cline { 2 - 5 } & Total & 26.6 & 4.6 & \\
\hline
\end{tabular}


Table 2 - Results from the chi-square test.

\begin{tabular}{|c|c|c|c|c|c|c|c|}
\hline \multirow{3}{*}{ Variable } & \multicolumn{4}{|c|}{ Group } & & & \multirow{3}{*}{ p } \\
\hline & \multicolumn{2}{|c|}{ Control } & \multicolumn{2}{|c|}{$\begin{array}{c}\text { Calcifying } \\
\text { tendinopathy }\end{array}$} & \multicolumn{2}{|c|}{ Total } & \\
\hline & $\mathrm{n}$ & $\%$ & $n$ & $\%$ & $\mathrm{n}$ & $\%$ & \\
\hline Sex & & & & & & & 0.592 \\
\hline Female & 31 & 49.2 & 28 & 44.4 & 59 & 46.8 & \\
\hline Male & 32 & 50.8 & 35 & 55.6 & 67 & 53.2 & \\
\hline Smoking & & & & & & & 0.159 \\
\hline No & 49 & 77.8 & 55 & 87.3 & 104 & 82.5 & \\
\hline Yes & 14 & 22.2 & 8 & 12.7 & 22 & 17.5 & \\
\hline Gallstones & & & & & & & 0.510 \\
\hline No & 59 & 93.7 & 57 & 90.5 & 116 & 92.1 & \\
\hline Yes & 4 & 6.3 & 6 & 9.5 & 10 & 7.9 & \\
\hline Gout & & & & & & & $0.365^{*}$ \\
\hline No & 62 & 98.4 & 59 & 93.7 & 121 & 96.0 & \\
\hline Yes & 1 & 1.6 & 4 & 6.3 & 5 & 4.0 & \\
\hline Renal lithiasis & & & & & & & 0.001 \\
\hline No & 57 & 90.5 & 42 & 66.7 & 99 & 78.6 & \\
\hline Yes & 6 & 9.5 & 21 & 33.3 & 27 & 21.4 & \\
\hline Total & 63 & 100 & 63 & 100 & 126 & 100 & \\
\hline
\end{tabular}

\section{DISCUSSION}

The etiology of calcifying tendinopathy remains unknown, as do its associations with other comorbidities. There are few reports in the literature on conditions correlated with calcifying tendinopathy. Harvie et $\mathrm{al}^{(7)}$ reported that calcifying tendinopathy was associated with hormonal abnormalities and/or autoimmune diseases such as hypothyroidism, diabetes mellitus and rheumatoid arthritis. However, there are no reports on association between calcifying tendinopathy and the disorder examined in this study.

The frequency of calcifying tendinopathy is significantly higher in manual workers, in the presence of diabetes $(25 \%)$ and in patients with kidney failure, in whom the prevalence may reach $50 \%{ }^{(8-10)}$.

According to Harvie et $\mathrm{al}^{(7)}$, from an analysis on 102 patients with calcifying tendinopathy of the shoulder, approximately $65 \%$ of the patients had already been diagnosed previously with some type of endocrine disease, while 19\% were undergoing treatment for some type of autoimmune disease (hypothyroidism, rheumatoid arthritis or diabetes mellitus). Among the women, $68 \%$ had already undergone some type of treatment for menstrual disorders. All these rates were significantly higher than in the general population. Moreover, these authors reported that the cases of calcifying tendinopathy associated with endocrine diseases were correlated with earlier development of tendinopathy, longer natural histories of evolution and greater resistance to conservative treatment.

According to the literature, nephrolithiasis is one of the commonest diseases of the urinary tract, with incidence of between 5 and $15 \%$ of the population and prevalence of 2 to $3 \%$ in the general population $^{(11,12)}$. In our control group, we observed a prevalence of $9.5 \%$, while in the group of patients with calcifying tendinopathy, the prevalence was $33 \%$. These data were shown to be statistically significant, with p-value $=0.001$.

The prevalence of cholelithiasis varies according to geographical location and the population group, but it has been estimated that it affects 10 to $25 \%$ of American adults ${ }^{(13,14)}$. In Brazil, studies have reported prevalences of 3.9 to $9.3 \%{ }^{(15,16)}$. In our control group, we observed a prevalence of $6.3 \%$, while in the group of patients with calcifying tendinopathy the prevalence was $9.5 \%$, without statistical significance when compared ( $p>0.005)$.

In a survey conducted in the United States between 1988 and 1994, it was estimated that around $2 \%$ of the men over the age of 30 years and of the women over the age of 50 years had a diagnosis of gout. Among Western men, it has been calculated that 1 to $2 \%$ have this disease ${ }^{(17)}$. In our control group, we observed that the prevalence of gout was $1.6 \%$, while in the group of patients with calcifying tendinopathy, the prevalence was $6.3 \%$, without statistical significance when compared $(\mathrm{p}>0.005)$.

It is important to emphasize that most studies on the prevalence of renal lithiasis and gallstones have been based on ultrasound or necropsy findings, which include a large number of patients with these diseases but who were asymptomatic. In the present study, since we only asked the patients about their previous histories of symptomatic diseases, the number of individuals with renal lithiasis may even have been underestimated.

Most authors have generally agreed that females are more affected by calcifying tendinopathy of the shoulder ${ }^{(1,2)}$. However, among the patients in our study, males accounted for $56 \%$ of the cases, although this finding was not statistically significant $(\mathrm{p}>0.005)$.

The other variables in this study (age, BMI and smoking) also did not show any statistical differences between the groups. 


\section{CONCLUSION}

Although the etiology of calcifying tendinopathy remains unknown, we believe that reports on its associations with other comorbidities may help towards understanding the disease. We noted that there was a high and significant association between calcifying tendinopathy of the shoulder and renal lithiasis, given that we found renal lithiasis in 33\% of the individuals with calcifying tendinopathy of the shoulder, while the prevalence of renal lithiasis among the control group individuals was $9 \%$. Thus, we believe that there may be mechanisms in common in the physiopathology of these disorders.

Our line of research should be continued to include an even larger number of patients and a more detailed study on the physiopathology of calcifying tendinopathy and renal lithiasis, in an attempt to create new perspectives for prevention, diagnosis and treatment of calcifying tendinopathy of the shoulder.

\section{REFERÊNCIAS}

1. Gosens T, Hofstee DJ. Calcifying tendinitis of the shoulder: advances in imaging and management. Curr Rheumatol Rep. 2009;11(2):129-34.

2. Uhthoff HK, Loehr JF. Calcific tendinitis. In: Rockwood CA, Matsen FA 3rd, editors. The shoulder. 4nd ed. Philadelphia: Saunders; 2009. p. 1277-307.

3. Ogon P, Bornebusch B, Maier D, Jaeger M, Izadpanah K, Köstler W, Südkamp NP. Tendinosis calcarea der schulter. Obere Extremität. 2010;5(6):115-24.

4. Uhthoff HK, Loehr JW. Calcific tendinopathy of the Rotator Cuff: Pathogenesis, Diagnosis, and Management. J Am Acad Orthop Surg. 1997;5(4):183-91.

5. Sengar DP, McKendry RJ, Uhthoff HK. Increased frequency of HLA-A1 in calcifying tendinitis. Tissue Antigens. 1987;29(3):173-4.

6. Gärtner J. [ls tendinosis calcarea associated with HLA-A1?]. Z Orthop Ihre Grenzgeb. 1993;131(5):469.

7. Harvie P, Pollard TC, Carr AJ. Calcific tendinitis: natural history and association with endocrine disorders. J Shoulder Elbow Surg. 2007;16(2):169-73.

8. Kaklamanis P, Rigas A, Giannatos J, Matsas S, Economou P. Letter: Calcification of the shoulders and diabetes mellitus. N Engl J Med. 1975;293(24):1266-7.

9. Andresen J, Nielsen HE. Juxta-articular erosions and calcifications in patients with chronic renal failure. Acta Radiol Diagn (Stockh). 1981;22(6):709-13.

10. Mavrikakis ME, Drimis S, Kontoyannis DA, Rasidakis A, Moulopoulou ES,
Kontoyannis S. Calcific shoulder periarthritis (tendinitis) in adult onset diabetes mellitus: a controlled study. Ann Rheum Dis. 1989;48(3):211-4.

11. Bezerra C, Anderson MIP, Prando D, Souza TF. Nefrolitíase: Abordagem urológica. In: Diretrizes Clínicas na Saúde Suplementar. Rio de Janeiro: Agencia Nacional de Saude Suplementar, Associação Medica Brasileira; 2009. p. 107.

12. Hiatt RA, Dales LG, Friedman GD, Hunkeler EM. Frequency of urolithiasis in a prepaid medical care program. Am J Epidemiol. 1982;115(2):255-65.

13. Santos JSS, Sankarankutty AK, Salgado Júnior W, Kemp R, Módena JLP, Elias Júnior J, et al. Colecistectomia: aspectos técnicos e indicações para o tratamento da litíase biliar e das neoplasias. Medicina (Ribeirão Preto) 2008;41 (4): 429-44.

14. Everhart JE, Khare M, Hill M, Maurer KR. Prevalence and ethnic differences in gallbladder disease in the United States. Gastroenterology. 1999;117(3):632-9.

15. Coelho JC, Bonilha R, Pitaki SA, Cordeiro RM, Salvalaggio PR, Bonin EA, et al. Prevalence of gallstones in a Brazilian population. Int Surg. 1999;84(1):25-8.

16. Kramer HM, Curhan $\mathrm{G}$. The association between gout and nephrolithiasis: the National Health and Nutrition Examination Survey III, 1988-1994. Am J Kidney Dis. 2002;40(1):37-42

17. Cruz BA. Atualização em reumatologia: gota. Rev Bras Reumatol. $2006 ; 46(6) ; 419-22$ 